\title{
Provocative Discography in Low Back Pain Patients With or Without Somati- zation Disorder: A Randomized Prospective Evaluation
}

\author{
Laxmaiah Manchikanti, MD*, Vijay Singh, MD\#, Vidyasagar Pampati, MSc ${ }^{\star *}$, Bert Fellows, MA, \\ Carla Beyer, RN"\#, Kim Damron, RN"\#, and Kim A. Cash, RT*
}

Recent reports of provocative discography not only instill confusion, but also create numerous questions about its value in evaluating low back pain. It was reported that provocative discography produced pain in patients who were not suffering with low back pain but suffering with somatization disorder and depression.

This study was designed to evaluate 50 randomly assigned patients, with 25 patients in Group I without somatization disorder and 25 patients in Group II with diagnosis of somatization disorder. In addition, depression, generalized anxiety disorder and combinations thereof were also evaluated. All patients underwent discography, investigating two to three discs in each patient. All studies included a control level with a disc that did not produce the patient's pain upon injection of contrast medium. Provocation with exact pain reproduction concordant with the symptom complex upon injection of contrast into the disc was considered positive. Any other response, with or without pain, was considered negative. Results showed positive provocative discogra-

Provocative discography is utilized in some patients to determine the cause of low back pain. However, the controversy surrounding discography, believed to have been resolved (1-3), resurfaced with publications of Carragee et al (4-9), attempting to instill confusion and create numerous questions about the value of provocative discography in evaluating low back pain. Carragee (4) questioned the objectivity of provocative discography. Carragee et al (5) first reported a review of their discography experience and found cases that appeared to be false-positive, in which injections meeting strict criteria for discogenic pain on

From Pain Management Center of Paducah, Paducah, Kentucky and Pain Diagnostic Associates, Niagara, Wisconsin. *Medical Director, **statistician, ${ }^{\#}$ clinical coordinators, "radiological technologist, and ${ }^{\Omega}$ psychologist at the Pain Management Center of Paducah. "Medical Director at Pain Diagnostic Associates. Address correspondence: Laxmaiah Manchikanti, MD, 2831 Lone Oak Road, Paducah, Kentucky 42003. E-mail: drm@ asipp.org phy in $46 \%$ of the patients in the somatization group compared to $54 \%$ in the non-somatization group; in $46 \%$ of patients with depression compared to $54 \%$ of patients without depression; in 15 of 30 patients with generalized anxiety disorder; in 11 of 20 patients without generalized anxiety disorder; and in $42 \%$ of patients with combined somatization and depression, with negative discography in $58 \%$ of the patients.

It is concluded that provocative discography provides similar results in patients with or without somatization, with or without depression, with somatization but with or without depression or with other combinations of the psychological triad of somatization disorder, depression, and generalized anxiety disorder.

Keywords: Provocative discography, somatization disorder, depression, psychosomatic response, psychophysiologic response, false-positive response

follow-up revealed other causes of the patient's back pain, including spinal tumor, sacroiliac joint disease, and emotional problems. Block et al (10) reported psychological influences, perhaps causing false-positive results. Ohnmeiss et al (11) also related pain drawings with nonorganic features being associated with possible falsepositive injections. Heggeness et al (12) reported a high (72\%) incidence of concordant pain with discography of the previously operated level, in patients presenting with disabling back pain who had previously undergone surgical treatment for herniated nucleus pulposus.

Carragee et al (6-8) were interested in older subjects with age-related changes in the lumbar spine, some chronic pain syndromes unrelated to the spine, some emotional and behavioral problems, and some compensation issues. Carragee et al (7) evaluated a group of asymptomatic patients and demonstrated that discography was painful in $10 \%$ of the pain free group, $40 \%$ of the chronic cervical pain group, and $83 \%$ of the somatization group. Further, Carragee et al (7) expounded on the hypothetical category 
defined by Walsh et al (13). They (7) evaluated 26 individuals, with a mean age of 43 years, with no history of low back pain. Of these, 10 were pain-free; 10 had chronic neck and arm pain, but no low back symptoms; and 6 had primary somatization disorders without low back symptoms. These researchers (7) showed that significant positive pain response and pain related behavior with discography were found in $10 \%$ of the pain-free group, $40 \%$ of the chronic cervical pain group, and $83 \%$ of the somatization disorder group completing the injections. Twentyfour subjects had negative control discs. Discs with annular disruption were more likely to be painful on injection, particularly in those individuals with ongoing compensation issues, chronic pain, or normal psychological testing scores. To evaluate somatization and abnormal psychological futures, Carragee et al (7) employed various psychometric tests including the Zung depression scale, modified somatic pain questionnaire, and medication scales, with each subject at the interview session before discography. Overall, 30 patients were enrolled in the study; however, discograms were performed only on 26 , with a dropout rate of $11.5 \%$. A positive disc injection strongly correlated with elevated modified somatic pain questionnaire and Zung scores.

Factors such as depression, anxiety, and excessive somatic perception are recognized as actively contributing to a patient's perception of pain (14-23). Somatization disorder and depression are complex, psychological disorders. In simple terms, patients with somatization may present to physicians hoping to obtain medical attention and symptomatic treatment.

Somatization is an extremely common phenomenon, with approximately $60 \%$ to $80 \%$ of physically healthy people, including medical professionals, experiencing somatic symptoms in any given week (24). Similarly, major depression is not only common, but also frequently reported in association with somatization $(16,18,20)$. The prevalence of somatization disorder and depression in chronic pain patients varies highly, ranging from $0 \%$ to $16.2 \%$ for somatization $(18,21-23,25-32)$, and $18 \%$ to $64 \%$ for depression (26, 33-39).

The association between chronic pain and depression remains a complex one. Depression may refer to a temporary bad mood, a reaction to concurrent stresses or losses, a chronic state of dysthymia, or "major depression." While Greenough and Fraser (40) concluded that the combination of the modified somatic perception questionnaire (MSPQ) and Zung depression scale yielded specificities and sensitivities of $91 \%$ and $84 \%$ for men and $96 \%$ and $85 \%$ for women, respectively; Deyo et al (41) reported the lack of correlation between MSPQ with functional outcomes and only weak association with pain outcomes, concluding that the MSPQ appears to be reliable and valid; but the somatic perceptions it measures may have little relation to patient outcomes. Similarly, the constructive validity of the Zung self-rating depression scale was questioned by Schotte et al (42) whereas Steuer et al (43) felt that, while there was no relationship found between health ratings and depression scores, a significant association emerged between a somatic subscale, specifically the single item of fatigability, physician's rating of health, and depression scores. The modified somatic perception questionnaire, which was specifically derived for use with chronic back pain patients, is a subjective test with a final 13-item scale which was derived from a pilot study of 102 chronic back pain patients. The MSPQ was compared with the Zung depression scale and the first three clinical scales of the Minnesota Multiphasic Personality Inventory (MMPI) (44). The Zung depression scale is frequently utilized to evaluate the patient's depression, whereas, a modified somatic pain questionnaire is utilized to evaluate somatization (44-46). The modified somatic perception questionnaire and Zung depression scales were correlating only in $50 \%$ of the patients, which indicates that these are two different types of tests evaluating two different variables.

Somatization disorder may be accurately evaluated either by MMPI or Millon Clinical Multiaxial Inventory (MCMI). Carragee et al (7) contented that careful psychological screening is valuable for patients undergoing discography. However, this study failed to demonstrate appropriate evaluation for somatization disorder and also failed to demonstrate a high degree of false-positive discography in a clinically irrelevant manner. Since discography in the asymptomatic group would not be used for any type of interventional therapy, this is, at best, an artificial exercise (9). Further questions may be raised with regards to the surgical interventions these patients already have undergone and their appropriateness.

Tsou (47) elaborated on the clinical parameters of positive provocation lumbar discography. The first essential element is the presence of back pain, with suspected origin from the spinal column. The suspicion is aroused by the fact that the patient has lower back pain exacerbated by the increase of intradiscal pressure. In addition, he stated that, in the absence of these findings, a clinician is not likely to order provocation discography. 
Since as clinicians we do not perform provocative discography in patients without back pain, it is impossible to confirm or contradict the results of Carragee et al (7). However, this study continues to cover provocative discography with a smoke screen. Hence, we have undertaken this prospective, randomized evaluation of provocative discography to evaluate the influence of somatization and depression on positive and negative provocative discography; however, only in patients with back pain without prior history of surgical intervention, who were negative for diagnostic facet joint blocks and therapeutic epidural injection.

\section{METHODS}

The study was designed to evaluate 50 patients, from a sample of 150 patients undergoing discographic evaluation after testing negative for facet joint mediated pain and failing to respond to fluoroscopically directed epidural steroid injections, 25 patients without somatization disorder (Group I) and 25 patients with somatization disorder (Group II), selected by computerized randomization. Patients younger than 18 years or older than 90 years, those who exhibited progressive neurological deficits, those who had had pain for less than 6 months or those who had undergone previous lumbar surgery were excluded. All patients were negative for facet joint mediated pain and failed to respond to fluoroscopically directed epidural steroid injections on one to three occasions. Failure was considered as response lasting less than 1 week with each injection or less than 1 month's cumulative relief. All 50 patients underwent psychological testing with MCMI III. All the patients provided informed choice and consent concerning the nature of the study and associated complications with discography. All procedures were performed under fluoroscopy by one physician in a sterile operating room in an ambulatory surgery setting. The procedure included appropriate preparation with intravenous access, sterile preparation and appropriate sedation with small doses of midazolam. No narcotics were administered. Provocative discography was adapted as the test for discogenic pain in accordance with the position statement on discography of the Executive Committee of the North American Spine Society (48). Simple criteria based on the assertion that discography is the sole direct method that distinguishes symptomatic versus asymptomatic discs were adapted. Provocation with exact pain reproduction, concordant with the symptom complex upon injection of contrast into the disc, was considered positive. Any other response with or without pain was considered negative.
Discography usually was initiated at the lower two lumbar levels. At least two discs, but up to three, were studied in each patient. All studies included a control level - i.e., a disc that did not reproduce the patient's pain upon injection of contrast medium. During provocative discography, all patients were assessed for pain response. Discs were graded either positive or negative, irrespective of morphologic appearance, based on pain response.

Data were recorded on a database using Microsoft ${ }^{\circledR}$ Access ${ }^{\circledR}$. The SPSS Version 9.0 statistical package was used to generate the frequency tables, and the chi-squared statistic was used to test the significance difference between groups. Student's t test was used to test mean differences between groups. Paired test was used to compare the pre- and postreatment overall health status. Results were considered statistically significant if the $P$ value was less than 0.05 .

\section{RESULTS}

Data were evaluated for patient characteristics, the number of discs evaluated and results of provocative discography, either negative or positive. In addition to this, the results were also correlated and compared, not only with nonsomatization and somatization groups, but also with patients with or without depression; with or without generalized anxiety disorder; with a combination of somatization with anxiety or depression; and finally, with the presence or absence of all three conditions.

\section{Patient Characteristics}

Demographic data are shown in Table 1, with no significant differences noted among both groups in terms of gender, age, weight, height, mode of onset of pain, duration of pain, and pain ratio.

\section{Psychological Characteristics}

Data on psychological abnormalities from both study groups are described in Table 2. Results show that depression was prevalent in $52 \%$ of the patients, whereas generalized anxiety disorder was prevalent in $60 \%$ of the patients. In contrast, a combination of somatization and depression was present in $24 \%$ of the patients; whereas somatization and generalized anxiety disorder were present in $40 \%$ of the patients. Combined depression and generalized anxiety disorder and somatization disorder and generalized anxiety disorders were present in $36 \%$ and $22 \%$ of the patients, consecutively. 
Table 1. Patient characteristics

\begin{tabular}{|c|c|c|c|}
\hline Number of patients & & $\begin{array}{c}\text { Group I } \\
\text { Nonsomatization } \\
\text { N=25 }\end{array}$ & $\begin{array}{c}\text { Group II } \\
\text { Somatization } \\
\text { N=25 }\end{array}$ \\
\hline \multirow{2}{*}{ Gender } & Male & $36 \%(09)$ & $44 \%(11)$ \\
\hline & Female & $54 \%(16)$ & $56 \%(14)$ \\
\hline \multirow{2}{*}{ Age (yrs.) } & Range & $24-66$ & $26-57$ \\
\hline & Mean + SEM & $41.4+2.08$ & $42.7+162$ \\
\hline \multirow{2}{*}{ Weight (lbs.) } & Range & $120-265$ & $102-340$ \\
\hline & Mean + SEM & $179.0+8.07$ & $177.8+10.09$ \\
\hline \multirow{2}{*}{ Height (inches) } & Range & $62-74$ & $61-72$ \\
\hline & Mean + SEM & $67.6+0.61$ & $66.2+0.62$ \\
\hline Body mass index & & $27.6+1.28$ & $28.4+1.59$ \\
\hline \multirow{4}{*}{ Mode of onset of pain } & Occupational & $28 \%(7)$ & $44 \%(11)$ \\
\hline & Motor vehicle accident & $24 \%(6)$ & $12 \%(3)$ \\
\hline & Nonoccupational & $16 \%(4)$ & $4 \% \quad(1)$ \\
\hline & Gradual onset & $32 \%(8)$ & $40 \%(10)$ \\
\hline \multirow{2}{*}{ Duration of pain (months) } & Range & $6-300$ & $6-264$ \\
\hline & Mean + SEM & $72+15.6$ & $92+16.6$ \\
\hline \multirow{4}{*}{ Pain ratio } & Back pain only & $4 \%(1)$ & $8 \%(2)$ \\
\hline & Back worse than leg pain & $48 \%(12)$ & $40 \%(10)$ \\
\hline & Back and leg pain equal & $32 \%(8)$ & $40 \%(10)$ \\
\hline & Leg pain worse than back pain & $16 \%(4)$ & $12 \%(3)$ \\
\hline
\end{tabular}

\section{Discography Characteristics}

Forty-eight patients underwent discography at three levels; the remaining two patients underwent discography at two levels. None underwent discography at more than three levels. The results of discography are shown in Table 3.

Fourteen, or 54\%, of patients in Group I (nonsomatization group) and 12 , or $46 \%$, of patients in Group II (somatization group) were judged to be positive; whereas the remaining patients in each group were judged to be negative. There were no significant differences noted between nonsomatization and somatization groups with regards to the positive discs; hence, we consider that there were no false-positives.

Table 2. Number of patients with psychological abnormalities from study groups

Condition

Depression

Generalized anxiety disorder

Somatization disorder and depression

Somatization disorder and generalized anxiety disorder

Depression and generalized anxiety disorder

Somatization disorder, depression and generalized anxiety disorder

Atleast one condition positive
Percent (Number)

$52 \%(26)$

$60 \%$ (30)

$24 \%$ (12)

$40 \%$ (20)

$36 \%(18)$

$22 \%(11)$

$84 \%(42)$ 
Table 3. Distribution of somatization disorder, depression, generalized anxiety disorder by outcome of discography

\begin{tabular}{|c|c|c|c|}
\hline \multirow[t]{3}{*}{ Somatization disorder } & & $\begin{array}{c}\text { Discography } \\
\text { Positive }(\mathrm{N}=26)\end{array}$ & $\begin{array}{c}\text { Discography } \\
\text { Negative }(\mathrm{N}=24)\end{array}$ \\
\hline & Positive & $46 \%$ (12) & $54 \%(13)$ \\
\hline & Negative & $54 \%(14)$ & $46 \%$ (11) \\
\hline \multicolumn{4}{|l|}{ Depression } \\
\hline & Positive & $46 \%(12)$ & $58 \%(14)$ \\
\hline & Negative & $54 \%(14)$ & $42 \%(10)$ \\
\hline \multicolumn{4}{|l|}{ Anxiety } \\
\hline & Positive & $58 \%(15)$ & $63 \%$ \\
\hline & Negative & $42 \%$ & $37 \%$ (9) \\
\hline \multicolumn{2}{|l|}{ Somatization disorder and depression } & $42 \%(5)$ & $58 \%(7)$ \\
\hline \multicolumn{2}{|l|}{ Somatization disorder and generalized anxiety disorder } & $50 \%(10)$ & $50 \%(10)$ \\
\hline \multicolumn{2}{|l|}{ Generalized anxiety disorder and depression } & $50 \%(9)$ & $50 \%(9)$ \\
\hline \multicolumn{2}{|l|}{$\begin{array}{l}\text { Somatization disorder, generalized anxiety disorder and } \\
\text { depression }\end{array}$} & $45 \%(5)$ & $55 \%(6)$ \\
\hline \multicolumn{2}{|l|}{ At least one condition positive } & $48 \%(20)$ & $52 \%(22)$ \\
\hline \multicolumn{2}{|l|}{ No psychological condition } & $75 \%(6)$ & $25 \%$ \\
\hline
\end{tabular}

The next comparison was between patients with or without depression. Provocative discography was positive in 12 , or $46 \%$, of patients with depression and in 14 , or $54 \%$, of patients who were negative for depression, with no significant difference noted between both groups of patients.

Similarly, the presence or absence of generalized anxiety disorder was also compared with positive and negative provocative discography. A total of 30 patients were positive for generalized anxiety disorder. Of these, 15 patients were shown to be positive for provocative discography, with an equal number of patientes shown to be negative. Similarly, there was no significant differences noted among the patients who were negative for generalized anxiety disorder, with discography-positive patients at 11 and negative patients at 9 .

Subsequently, a combination of somatization and depression was also compared. There were 12 patients who showed combined somatization and depression. Among these, five patients were shown to be positive for provocative discography; whereas seven were shown to be negative, with no difference noted between both groups of pa- tients.

Similarly, 20 patients were positive for somatization disorder and generalized anxiety disorder. Of these, 10 patients were positive for discography; and 10 were negative, with equal distribution among both. A combination of generalized anxiety disorder and depression was seen in 18 patients. Of these, nine patients were positive for provocative discography; whereas nine patients were negative for provocative discography.

A combination of somatization disorder, generalized anxiety disorder, and depression was present in a total of 11 patients. Of these, five patients were positive for provocative discography; whereas six were negative, with no difference noted.

We also evaluated patients who were positive for at least one of the three conditions. There were 42 patients who fit into this category with the presence of at least one condition of either somatization disorder, depression or generalized anxiety disorder. Of these, 20 patients were positive for provocative discography; whereas 22 patients were 
negative for provocative discography.

Finally, there were only eight patients without any of the three psychological conditions. Of these, six patients were discography positive and two patients were discography negative, with no significant differences noted among both groups of patients.

\section{Psychological Variables}

Correlation of psychological variables is shown in Table 4. These included correlation between depression and generalized anxiety disorder; between somatization disorder and depression; and between somatization disorder and generalized anxiety disorder. There was no significant correlation noted between depression and generalized anxiety disorder, or between depression and somatization disorder. However, there was significant correlation ( $P=0.004)$ between somatization disorder and generalized anxiety disorder.

\section{DISCUSSION}

Somatization disorder is a complex, psychiatric diagnosis. Aronoff et al (15) questioned the validity of pain disorder and somatization disorder as valid diagnostic entities. They defined somatization as not being the psychiatric diagnosis of somatization disorder, formerly known as Briquettes syndrome. In order to meet the full criteria of somatization disorder, a patient must have a history of many physical complaints beginning before age 30, which occur over a period of several years and result in seeking treatment or significant impairment in social, occupational, or other important areas of functioning. In addition, the patient must also have four pain symptoms, two gastrointestinal symptoms, one sexual symptom, and one pseudoneurologic symptom. Further, a patient with somatization and pain disorder also should meet the criterion that after appropriate physical investigation, each of the previously named symptoms cannot be fully explained by a known general medical condition or by the direct effects of a substance; only then criteria for somatization disorder are considered

Table 4. Correlation among various psychological conditions

A. Correlation between depression and generalized anxiety disorder

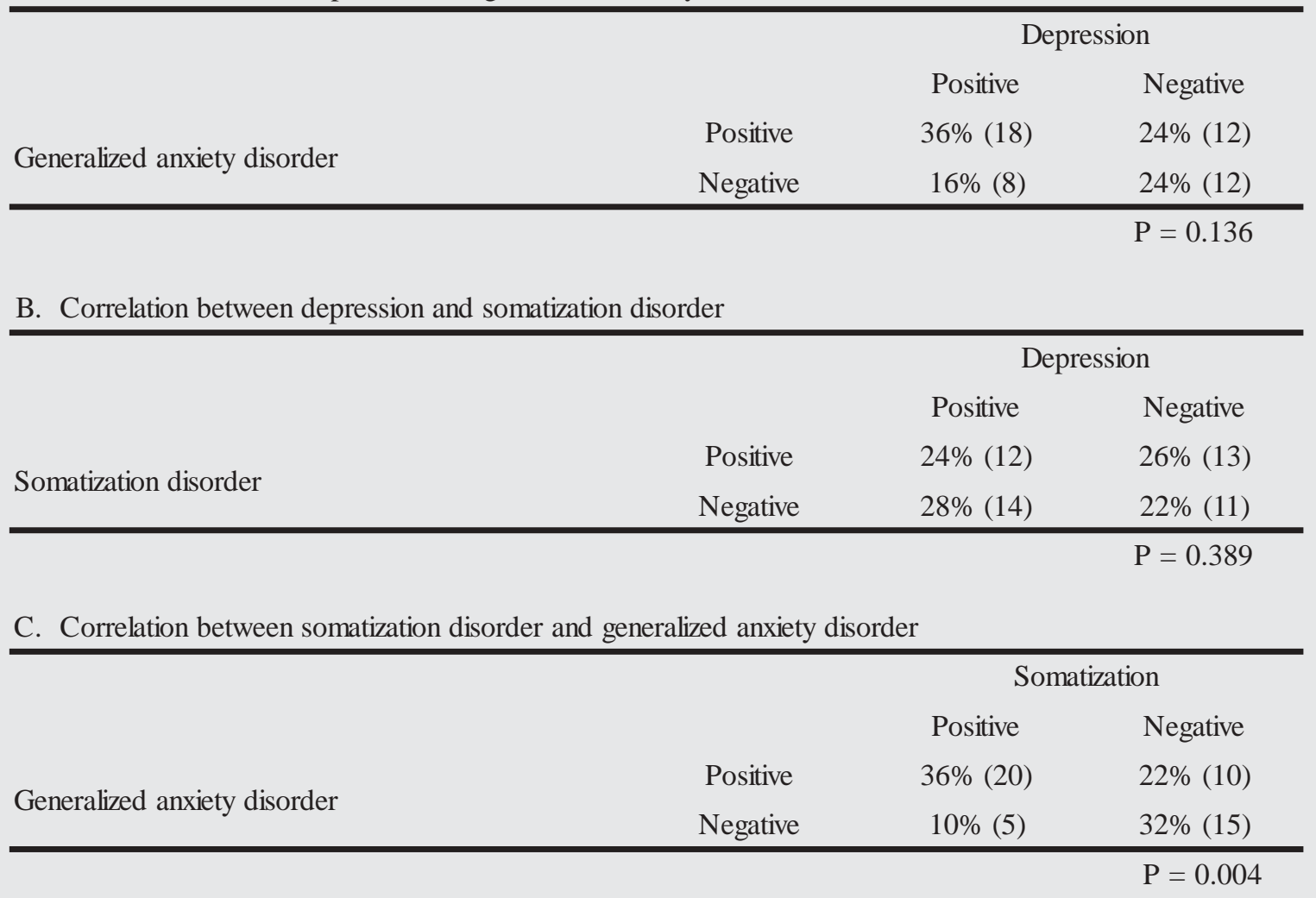


to have been met (49).

Above all, in order to diagnose a patient with somatization disorder when there is a related general medical condition, the physical complaints or the social or occupational impairments that result from the general medical condition should be in excess of what would be expected from history, examination or laboratory findings $(15,49)$. Lipowski (16) conceptualized somatization as "A tendency to experience and communicate somatic distress and symptoms unaccounted by pathologic findings to attribute them to physical illness, and to seek medical health for them." Sullivan and Katon (17) defined somatization as, "An ubiquitous and diverse process linking the physiology of distress and psychology of symptom presentation" in a primary care setting. Aronoff (50) viewed somatization with the perspective of Sullivan and Katon (17) when discussing pain conditions such as myofascial pain syndromes or fibromyalgia.

Psychophysiologic, as well as psychosomatic responses, may be present with somatization disorder, even though the two terms are not interchangeable. Aronoff et al (15) described that in a psychosomatic response, a patient's psychological state interacts with certain predisposed physical vulnerabilities, such as in the development of an ulcer. In contrast, in a psychophysiologic response, which is more commonly seen with individuals without the requirement of a physical predisposition, individuals experience a tension-type headache or gastrointestinal upset. In addition, somatization is also a likely process occurring within a pain disorder itself.

Patients with a tendency towards somatization may present to the physicians hoping to obtain medical attention and symptomatic treatment. This tendency essentially begins in childhood and is believed to account for a significant proportion of medical care utilization in adults. It is stated that approximately one third to two thirds of the patients in primary care settings have unexplained somatic symptoms (51). These patients are described as being heterogeneous and present with an assortment of unexplained symptomatology, psychosocial distress, psychophysiologic syndromes such as irritable bowel syndrome, chronic pain, hypochondriac worry, a history of sexual and physical abuse and bodily manifestations of psychiatric disorders. These patients are frequently labeled as "somatizers," not based on specific symptom presentations, but because they repeatedly seek the counsel of physicians in search of understanding, and yet no satisfactory medical explanations can be found. Fink et al (51) showed that between $22 \%$ and
$58 \%$ of the consecutive patients in primary care fulfilled the diagnostic criteria for a somatoform disorder. They correlated this with the prevalence of mental disorders in primary care patients, which was described as $14 \%$ and $36 \%(52,53)$.

The same confusion exists in the world of modern medicine with regards to chronic pain and chronic pain syndrome. Chronic pain, also known as persistent pain, the pain that persists beyond the expected healing time of an injury or an illness, is usually considered as pain experienced for more than 6 months (54-58). Chronic pain may be associated with psychological problems such as depression, generalized anxiety disorder, and other behavioral problems (54-58). However, chronic pain improperly diagnosed or inadequately treated can result in deteriorating coping skills and limitations and reduction in functional capacity.

In contrast, chronic pain syndrome is a complex condition with physical, psychological, emotional, and social components $(57,58)$. Both chronic pain and chronic pain syndrome can be defined in terms of duration and persistence of the sensation of pain, and presence or absence of psychological and emotional components. However, chronic pain syndrome, as opposed to chronic pain, has the added component of certain recognizable, psychological and socioeconomic influences, with characteristic psychological and sociological behavior patterns inherent in chronic pain syndrome that distinguish the two conditions (57). According to the Fifth Edition of the Guides to the Evaluation of Permanent Impairment, published in 2000 (58), the term chronic pain syndrome, even though not official nomenclature, is frequently used to describe the condition of an individual who is markedly impaired by chronic pain with substantial psychological overlay. These guides also state that chronic pain syndrome is largely a behavioral syndrome that affects a minority of those with chronic pain. It may best be understood as a form of abnormal illness behavior that consists mainly of excessive adoption of the sick role. The guides also caution that, while the term is useful in certain situations, it is not, however, a substitute for a careful diagnosis of physiologic, psychological, and conditioning components that comprise the syndrome. Hence, once again, it is cautioned that the term chronic pain syndrome must be used with caution, as grouping pain problems together under a general disorder may mask and leave untreated important physiologic differences (58). Thus, chronic pain may exist in the absence of chronic pain syndrome, but chronic pain syndrome always presumes the presence of chronic pain. The terminology rec- 
ommended by the International Association for the Study of Pain (IASP) has eliminated chronic pain syndrome from its glossary (56).

The IASP Task Force on Taxonomy and Classification of Chronic Pain, when defining pain terms, described that it is common in North America to find patients as having chronic pain syndrome. In this case, the Task Force believed that the words are being used as a diagnosis that usually implies a persistent pattern of pain that may have arisen from organic causes but which is now compounded by psychological and social problems resulting in behavioral changes. Even though the Task Force was asked to adopt such a label, particularly for use in billing in the United States, there was general agreement that this would not be desirable. The Task Force also noted that the term chronic pain syndrome is often, unfortunately, used pejoratively (56). However, the literature shows that chronic pain syndrome is not a common phenomenon in general, and is particularly very infrequent in the elderly (59). Hendler et al (60), after evaluating a number of cases which were referred to them as "psychosomatic" cases, found organic origin of the pain in $98 \%$ of the cases. In addition, Hendler and Kolodny (61) also estimated that the incidence of psychogenic pain is only 1 in 3,000 patients. Finally, with regards to specific patterns of low back and lower extremity pain, chronic low back pain has been described as a diagnostic dilemma in $85 \%$ of patients, even in experienced hands with all the available technology with the latest magnetic resonance imaging and electrophysiologic studies, ever-growing physical findings, and other noninvasive evaluations (54).

Some patients may prefer to report somatic symptoms over psychosocial concerns because they believe they will receive more medical attention, but others may simply experience distress somatically (15). However, the connection between the symptoms and life events is often not immediately evident to the patient or the physician (62). The reasons described as encouraging patients with psychological symptoms to present with somatic features include poor insight of the patients into their own emotional status (63). The medical community responds more sympathetically to physical rather than psychological distress, and insurance reimbursement patterns encourage the expression of illness versus psychological distress (64).

However, patients with genuine medical conditions may present with severe symptoms, in excess of what is normally expected with the condition or poor control of their condition, which is true with many chronic painful condi- tions, including low back pain and complex regional pain syndromes. In addition, somatization disorder is part of a complex disorder cluster of somatoform disorders, which also includes conversion disorders, somatoform pain disorder and hypochondriasis. Fishbain (18) described that the term somatization has become extremely common in the medical literature, yet there is little agreement about its definition. Sullivan and Katon (17) explained that somatization does not represent a specific psychiatric or medical diagnosis and does not necessarily imply that a psychiatric disorder must be present. Once again, somatization is not a specific diagnosis; hence, it does not have operational criteria by which the diagnosis can be reached. This has been detrimental to the study of somatization per se and has led to authors' using their own definitions and criteria with misinterpretations. Bridges and Goldberg (65) have recommended the use of criteria which include that the patients must seek help for somatic symptoms and not for psychologic manifestations of a psychiatric disorder, that patients must attribute their symptoms to medical illness, and that patients must report symptoms that justify psychiatric diagnosis. However, these criteria were entirely different from those described by various other authors including Lipowski (26). Somatization is an extremely common phenomenon, with approximately $60 \%$ to $80 \%$ of physically healthy people experiencing somatic symptoms in any given week (24). That may include a great number of medical professionals. Somatization can be, and most frequently is, comorbidly associated with physical diseases $(64,66)$. Surprisingly, but sadly, it also has been shown that patients identified as somatizers often suffer from chronic illness and die early (67).

Major depression is also frequently reported to be present independently and in association with somatization (16, 18, 20, 33-39). However, some investigators indicate that this observation may be overly simplistic (18). Chandler and Gerndt (68) have shown that a substantial number of elderly, depressed patients who allegedly had somatization disorder had, in reality, co-existing physical illness. In addition, when age and sex were controlled, patients suffering from depression were no more likely to have somatic complaints than patients who were diagnosed with other psychiatric illnesses. Therefore, it may be possible that the frequently reported association between depression and somatization reflects the preponderance of women and an increase in medical problems related to aging in the patient populations in which somatization is studied (18). Sullivan and Katon (17) described that somatization is very common; somatization frequently coexists with medical illness; a spectrum of severity from acute to chronic exists 
for somatization; and most somatization is transient and treatable. They also described three types of somatization reactions, which included somatization related to acute situational stress, somatization related to an acute psychiatric disorder or disorders, and somatization related to a chronic psychiatric disorder or disorders. Ford (69) compared multiple somatizaton similarities among various somatoform disorders, including hypochondriasis; conversion disorder; somatization disorder; pain disorder; undifferentiated somatoform disorder; somatoform disorder, not otherwise specified; and bony dysmorphic disorder; factitious disorders; and malingering, which all have been grouped together as somatizing disorder(s).

In specific reference to somatization in chronic patients, Sullivan and Katon (21) claimed that patients with chronic nonmalignant pain tend to have multiple nonpain physical complaints, based on review of family medicine studies. The literature indicates that these symptoms account for $30 \%$ to $40 \%$ of ambulatory medical visits, with only a small percentage of these patients having an identifiable organic etiology (70). The review of studies on pain in the literature also showed a high percentage of chronic pain patients demonstrating elevated hypochondriasis scores (25) and somatization scores (22) as measured by the illness behavior questionnaire and the modified somatic perception questionnaire, respectively. In addition, when patients with various types of chronic pain were compared with appropriate controls on somatization measures, the chronic pain patients were frequently shown to have greater somatization scores (18). This has been true for chronic low back among other painful conditions (22).

The diagnostic frequency of somatization disorders in chronic pain patients varied widely. Fishbain et al (26), in studying 283 patients, showed somatization disorder to be present in only $3.9 \%$ of the patients; whereas conversion disorder was present in $37.8 \%$ of the patients. Reich et al (27), in 43 patients, showed the frequency of somatization disorder in $5 \%$ of the patients; whereas psychogenic pain was diagnosed in $32 \%$ of the patients. Katon et al (28) in 37 patients diagnosed somatization disorder as present in $16.2 \%$ of the patients, whereas Larg (29) reported the incidence of somatization disorder as $8 \%$ in 50 patients in contrast to convulsion disorder in $8 \%$. Fishbain et al $(30,31)$, in studying a large population of 2,860 patients in one study, showed a $0.14 \%$ incidence of factitious disorders; however, no mention of somatization disorder. Finally, Polatin et al (37), studying 200 patients, showed a $1 \%$ incidence of somatization disorder and a $97 \%$ incidence of psychogenic pain/pain disorder. Thus, frequency of somati- zation disorder in chronic pain patients is highly variable, from $0 \%$ to $16.2 \%$ which is higher than in the general population.

Further, questions have been raised as to whether there is a relationship between somatization, secondary gain and pain. Fishbain et al (30) found only two studies $(23,32)$ that can be construed to address the relationship among secondary gain, somatization, and chronic pain. Cassisi et al (32) studied 250 patients, utilizing Symptom Checklist (SCL-90) and showed that all patients had elevated SCL90 scores; but Workers' Compensation patients demonstrated the highest level of somatization. Korbon et al (23), in contrast, studied patients with Workers' Compensation injuries, utilizing a somatic amplification rating scale which is designed to quantify nonorganic physical findings that indicate either conversion problems or malingering. They found that chronic pain patients with high somatic amplification rating scales scores were significantly more likely to be Workers' Compensation patients suffering with chronic pain.

Manchikanti et al (71) in evaluating characteristics of chronic low back pain in patients in an interventional pain management setting, showed that of the 200 patients included in the study, patients presenting to an interventional pain medicine setting are different from those presenting to either a neurosurgical or orthopedic surgical setting. In a chronic pain medicine program setting, patients were elderly, predominantly women, predominantly obese or overweight, predominantly suffering with a long duration of pain involving multiple regions, and presented with high intensity of pain. In addition, these patients also presented with significant psychological conditions and had undergone multiple modalities of treatments. Generalized anxiety disorder was seen most frequently, in $49 \%$ of the patients, with no significant difference between men and women; whereas somatization disorder was seen in $34 \%$ of patients, with no significant difference between men and women; depression or dysthymia were seen in $30 \%$ of patients, with no significant difference between men and women.

Sikorski et al (72), evaluating the psychological aspects of chronic low back pain in a structured, prospective study, determined the prevalence of somatization in a sample of 3100 patients with chronic low back pain using the Illness Behavioral Questionnaire (IBQ) and the MSPQ. They showed that $54 \%$ of the patients had four or more out of five abnormal illness indicators. The MSPQ values for the group were significantly above the control values in 
the literature. They also showed that $32 \%$ of pain diagrams were thought to be incompatible with an organic cause when assessed by an orthopedic surgeon and $62 \%$ when assessed by a psychiatrist.

However, incidence of higher levels of somatization in chronic pain patients has not been shown to translate into poor prognosis or false-positive results on diagnostic testing. Multiple reports have shown (73-75) improvement in psychological status following appropriate diagnosis and treatment of the painful condition. Block et al (10) evaluated the influence of psychological factors and discographic pain report. Significance of psychosocial factors in low back pain has been repeatedly demonstrated in the literature (76). It has been shown that elevated scores on the MMPI hypochondriasis (HS) and the hysteria (HY) scales have been found to predict the occurrence of job-related low back pain (77). In addition, the same characteristics, as well as other features assessed by MMPI, have predicted a poor response to surgery, and also to conservative care $(78,79)$. However, somatization has not been studied specifically in these disorders. Among chronic back pain patients, the most frequently found MMPI profiles are those containing elevated HS and HY scales (80). These profiles in general reflect excessive bodily concern, but without much emotional distress. These patients with these profiles may "Have multiple somatic complaints including headaches, chest pain, back pain and numbness or tremors of the extremities which increases in times of stress" (81). Thus, it is postulated that, if chronic low back pain patients are oversensitive to pain and other physical symptoms, poor treatment outcome may result. Bacon et al (22) concluded that $26 \%$ of the chronic low back pain patients met strict DSM-III criteria for a lifetime diagnosis of somatization disorder, reporting a lifetime history of 12 or more symptoms, compared to only $4.4 \%$ of controls. They also reported that major depression and alcohol dependency were significantly associated with increased severity of somatization and increased impairment; however, pain intensity was not related to greater somatic complaints. They concluded that symptoms of somatization are prevalent, but not chronic low back pain; and the pattern of these symptoms is reminiscent of the spectrum reported in other medical populations.

Back pain is induced with discography, similar to the patient's clinical symptoms. In evaluating this issue, Block et al (10) concluded that discographic pain reports are not only related to anatomic abnormalities, but are influenced by personality as assessed by the MMPI. They concluded that patients with elevated scores on the hypochondriasis, hysteria and depression scales may tend to overreport pain during discographic injection. They caution that among such patients, even those with a concordant computed tomography/disocgraphic image, selection of therapeutic modalities should be made with caution. However, Carragee et al (7) projected these clinical findings and performed provocation discography using a nonstandard clinical definition for false-positive discography. Most clinicians know that pressurization of asymptomatic degenerative discs may trigger some pain response.

Our results in two distinct groups of patients with or without somatization showed that there was no difference in provocative discography between the groups. There were 12 , or $46 \%$, of patients in the somatization disorder group, or Group II, with positive discography; whereas there were 13 , or $54 \%$, of patients in the negative group, with no significant differences. Thus, our results contradict the results of Carragee et al (7). Further, our study evaluated patients with definite diagnosis of somatization disorder or its absence by a valid and more elaborate psychological testing, resulting in comprehensive evaluation. Our study also showed that depression and generalized anxiety disorder were also fairly common in these patients. Various combinations of somatization disorder and depression, generalized anxiety disorder; depression and generalized anxiety disorder were also seen in significant number of patients. However, only a small number of patients presented with the complex triad of somatization disorder, depression and generalized anxiety disorder. Surprisingly, there were only nine patients who had none of the psychological disorders.

We also compared results of provocative discography in depressed patients, patients suffering with generalized anxiety disorder, somatization disorder and generalized anxiety disorder, somatization disorder and depression, generalized anxiety disorder and depression, patients with a complex triad of all three disorders and patients with only one positive psychological condition, as well as patients with no psychological conditions. Surprisingly, there were no differences noted in any of the aspects of psychological condition and positive or negative provocative discography. Further, we also assessed correlation between various conditions, including depression and generalized anxiety disorder, depression and somatization disorder, somatization disorder and generalized anxiety disorder. In contrast to the previous reports and the contention of various authors, there was no correlation noted between generalized anxiety disorder or depression and somatization. However, there was significant correlation between somatiza- 
tion disorder and generalized anxiety disorder.

Hence, the results of this study show that, while psychological symptoms are present in conjunction with physical problems, these do not result in positive provocative discography. Hence, these patients should not be refused care due to the results of psychological evaluation, as many of these patients concurrently suffer legitimate physical problems which tend to disappear following appropriate management of physical conditions

\section{CONCLUSION}

This study showed that provocative discography yielded similar results irrespective of the patient's psychological condition, with or without somatization disorder, with or without depression, and multiple other combinations of somatization disorder, depression, and generalized anxiety disorder. In addition, this study showed no significant correlation between somatization disorder and depression, depression and generalized anxiety disorder in this particular group of patients. However, it showed significant correlation between somatization disorder and generalized anxiety disorder. There were only a small number of patients without psychological diagnosis. Hence, the association of psychological conditions with a physical condition is a common phenomenon in managing chronic low back pain patients.

\section{ACKNOWLEDGEMENTS}

We would like to thank Denise Pratt and Tonie Hatton, transcriptionists, for their assistance with transcription of the manuscript.

\section{REFERENCES}

1. Fortin JD. Precision diagnostic disc injections. Pain Physician 2000; 3:271-288.

2. Holt EP Jr. The question of lumbar discography. $J$ Bone Joint Surg (Am) 1968; 50:720-726.

3. Holt EP Jr. Fallacy of cervical discography. Report of 50 cases in normal subjects. JAMA 1964; 188:799801.

4. Carragee EJ. Is lumbar discography a determinate of discogenic low back pain: Provocative discography reconsidered. Curr Rev Pain 2000; 4:301-308.

5. Carragee E, Tanner C, Vittum D et al. Positive provocative discography as a misleading finding in the evaluation of low back pain [abstract]. In Proceedings of the North American Spine Society, Chicago, IL, 1997:388.
6. Carragee EJ, Chen Y, Tanner CM et al. Provocative discography in patients after limited lumbar discectomy. A randomized study of pain response in symptomatic and asymptomatic subjects. Spine 2000; 25:3065-3071.

7. Carragee EJ, Tanner CM, Khurana $\mathrm{S}$ et al. The rates of false-positive lumbar discography in select patients without low back symptoms. Spine 2000; 25:13731381 .

8. Carragee EJ, Paragioudakis SJ, Khurana S. 2000 Volvo award winner in clinical studies. Lumbar high-intensity zone and discography in subjects without low back problems. Spine 2000; 25:2987-2992.

9. Wetzel FT. Rates of false-positive lumbar discography: Point of view. Spine 2000; 25:1381.

10. Block A, Vanharanta H, Ohnmeiss D et al. Discographic pain report: Influence of psychological factors. Spine 1996; 1:334-338.

11. Ohnmeiss DD, Vanharanta H, Guyer RD. The association between pain drawings and computed tomographic/discographic pain responses. Spine 1995; 20:729-733.

12. Heggeness MH, Watters WC, Gray PM. Discography of lumbar discs after surgical treatment for disc herniation. Spine 1997; 22:1606-1609.

13. Walsh T, Weinstein J, Spratt K et al. Lumbar discography in normal subjects: A controlled prospective study. J Bone Joint Surg 1990; 72A:10811088.

14. Tollison CD, Satterthwaite JR. Chronic benign pain: Diagnosis and behavioral management. J Musculoskeletal Med 1991; 8:55-66.

15. Aronoff GM, Tota-Faucette M, Phillips L et al. Are pain disorder and somatization disorder valid diagnostic entities. Curr Rev Pain 2000; 4:309-312.

16. Lipowski ZJ. Somatization and depression. Psychosomatics 1990; 31:13-21.

17. Sullivan M, Katon W. Somatization: The path between distress and somatic symptoms. Am Pain Soc J 1993; 2:141-149.

18. Fishbain DA. Somatization, secondary gain, and chronic pain: Is there a relationship? Curr Rev Pain 1998; 6:101-108.

19. American Geriatrics Society. The management of chronic pain in older persons: New guidelines from the American Geriatrics Society. J Am Geriatr Soc 1998; 46:128-150.

20. Katon W, Kleinman A, Rosen G. Depression and somatization a review. Part I. Am J Med 1982, 72:127135.

21. Sikorski JM, Stampfer HG, Cole RM et al. Psychological aspects of chronic low back pain. Aust N Z J Surg 1996; 66:294-297.

22. Bacon NM, Bacon SF, Atkinson JH et al. Somatization symptoms in chronic low back pain patients. Psychosom Med 1994; 56:118-127. 
23. Korbon GA, DeGood DE, Schroeder ME et al. The development of a somatic anmplication rating scale for low back pain. Spine 1987; 12:787-791.

24. Kellner R, Sheffield BR. The one-week prevalence of symptoms in neurotic patients and normals. Am J Psychiatry 1973; 130:102-105.

25. Pilowsky I, Spence ND. Patterns of illness behaviour in patients with intractable pain. J Psychosom Res 1975; 19:279-287.

26. Fishbain DA, Goldberg M, Meagher BR et al. Male and female chronic pain patients categorized by DSMIII psychiatric diagnostic criteria. Pain 1986; 26:181197.

27. Reich J, Rosenblatt RM, Tupen J. DSM-III: A new nomenclature for classifying patients with chronic pain. Pain 1983; 16:201-206.

28. Katon W, Egan K, Millder D. Chronic pain: Lifetime psychiatric diagnoses and family history. Am J Psychiatry 1985; 142:1156-1160.

29. Large RG. DSM-III Diagnosis in chronic pain- confusion or clarity? J Nerv Ment Dis 1986; 174:295302.

30. Fishbain DA, Cutler R, Rosomoff HL et al. Chronic pain disability exaggeration /malingering and submaximal effort research. Clin J Pain 1999; 15:244274.

31. Fishbain DA, Goldberg M, Rosomoff RS et al. More Munchausen with chronic pain. Clin J Pain 1991; 7:237-244.

32. Cassisi JE, Sypert GW, Lagara L et al. Pain disability and psychosocial function in CLBP subgroups: myofascial versus herniated disc. Neurosurgery 1993; 33:379-385.

33. Rush AJ, Polatin P, Gatchel RJ. Depression and chronic low back pain. Spine 2000; 25:2566-2571.

34. Magni G, Caldieron C, Rigatti-Luchini S et al. Chronic musculoskeletal pain and depressive symptoms in the general population: An analysis of the $1^{\text {st }}$ National Health and Nutrition Examination Survey data. Pain 1990; 43:299-307.

35. Dworkin RH, Gitlin MJ. Clinical aspects of depression in chronic pain patients. Clin J Pain 1991; 7:7994.

36. Von Korff M, Simon G. The relationship between pain and depression. Br J Psychiatry 1996; 30:101-108.

37. Polatin PB, Kinney RK, Gatchel RJ et al. Psychiatric illness and chronic low-back pain: The mind and the spine - which goes first? Spine 1993; 18:66-71.

38. Fishbain DA, Cutler R, Rosomoff HL et al. Chronic pain associated depression: Antecedent or consequence of chronic pain? A review. Clin J Pain 1997; 13:116137.

39. Banks SM, Kerns RD. Explaining high rates of depression in chronic pain: A diathesis-stress framework. Psychol Bull 1996; 119:95-110.

40. Greenough CG, Fraser RD. Comparison of eight psy- chometric instruments in unselected patients with back pain. Spine 1991; 9:1068-1074.

41. Deyo RA, Walsh NE, Schoenfeld LS et al. Studies of the modified somatic perceptions questionnaire (MSPQ) in patients with back pain. Psychometric and predictive properties. Spine 1989; 14:507-510.

42. Schotte CK, Maes M, Cluydts R et al. Effects of affective-semantic mode of item presentation in balanced self-report scales: Biased construct validity of the Zung Self-rating Depression Scale. Psychol Med 1996; 6:1161-1168

43. Steuer J, Bank L, Olsen EG et al. Depression, physical health and somatic complaints in the elderly: A study of the Zung Self-Rating Depression Scale. Gerontol 1980; 5:683-688.

44. Main C. The modified somatic perception questionnaire. J Psychosom Res 1983; 27:503-514.

45. Carragee EJ, Kim D. A prospective analysis of MRI findings in patients with sciatica and lumbar disc herniation: Correlation of outcomes with disk fragment and canal morphology. Spine 1997; 22:1650-1660.

46. Main C, Wood P, Hollis S et al. The distress and risk assessment method (DRAM): A simple patient classification to identify distress and evaluate the risk of a poor outcome. Spine 1992; 17:42-52.

47. Tsou PM. Letter to the editor. Spine 2001; 26:994995.

48. Guyer RD, Ohnmeiss DD. Contemporary concepts in spine care lumbar discography. Position statement from the North American Spine Society Diagnostic and Therapeutic Committee. Spine 1995; 20:2048-2059.

49. American Psychiatric Association: Diagnostic and Statistical Manual of Mental Disorders, Fourth Edition, Washington, D.C., American Psychiatric Association, 1994.

50. Aronoff GM. Psychiatric aspects of nonmalignant chronic pain: A new nosology. In Aronoff GM (ed). Evaluation and Treatment of Chronic Pain. Third Edition. Williams and Wilkins, Philadelphia, 1999; pp 291-300.

51. Fink P, Sørensen L, Engberg M et al. Somatization in primary care. Prevalence, health care utilization, and general practitioner recognition. Physhosomatics 1999; 40:330-338.

52. Üstün TB, Sartoius N. Mental illness in general health care: An international study. Geneva, World Health Organization, and New York, 1995.

53. Fink P, Jensen J, Borgquist L et al. Psychiatric morbidity in primary public health care. A Nordic multicenter investigation. Part I: method and prevalence of psychiatric morbidity. Acta Psychiatr Scand 1995; 92:409-418.

54. Manchikanti L, Singh V, Kloth D et al. Interventional techniques in the management of chronic pain: Part 2.0. Pain Physician 2001; 4:24-96. 
55. Pain. In Guides to the Evaluation of Permanent Impairment, Fourth Edition American Medical Association, Chicago, 1993, pp 303-311.

56. Merskey H, Bogduk N. Classification of chronic pain: Descriptions of Chronic Pain Syndromes and Definitions of Pain Terms. Second Edition. IASP Press, Seattle, 1994.

57. Rucker KS. Chronic Pain Evaluation. Butterworth/ Heinemann, Boston 2001.

58. Coccharella L, Andersson GBJ (eds). Pain. Guides to the Evaluation of Permanent Impairment, Fifth Edition American Medical Association, Chicago, IL, 2000, pp 565-591.

59. Corran TM, Farrell MJ, Helme RD et al. The classification of patients with chronic pain: Age as a contributing factor. Clin J Pain 1997; 13:207-214.

60. Hendler NH, Bergson C, Morrison C. Overlooked physical diagnoses in chronic pain patients involved in litigation. Part 2. Psychosomatics 1996; 37:509517.

61. Hendler NH, Kolodny AL. Using medication wisely in chronic pain. Patient Care 1992; May 15:125.

62. Epstein R, Quill T, McWhinney I. Somatization reconsidered. Arch Intern Med 1999; 59:215.

63. Sifineos PE. The prevalence of "alexithymic" characteristics in psychosomatic patients. Psychother Psychosom 1973; 22:255-262.

64. Aronoff GM. Psychodynamics and psychotherapy of the chronic pain syndrome. In Aronoff GM (ed). Evaluation and Treatment of Chronic Pain, Third Edition. Williams and Wilkins; Philadelphia, 1999, pp 83-290.

65. Bridges RN, Goldberg DP. Somatic presentation of DSM-III psychiatric disorders in primary care. $J$ Psychosom Res 1985; 29:563-569.

66. Ford CV. The somatizing disorders. Psychosomatics 1986; 27:327-337.

67. McFarland BH, Freeborn DK, Mullooly JP. Utilization patterns among long-term enrollees in a prepaid group practice health maintenance organization. Med Care 1985; 23:1221-1233.

68. Chandler JD, Gerndt J. Somatization, depression and medical illness in psychiatric inpatients. Acta Psychiatr Scand 1988; 77:67-73.
69. Ford CV. Dimensions of somatization and hypochondriasis. Neurologic Clin 1995; 13:241-253.

70. Kroenke K, Mangelsdorff A. Common symptoms inambulatory care: incidence, evaluation, therapy, and outcome. Am J Med 1989; 86:262-266.

71. Manchikanti L, Pampati V, Fellows B et al. Characteristics of chronic low back pain in patients in an interventional pain management setting: A prospective evaluation. Pain Physician 2001; 4:131-142.

72. Sikorski JM, Stampfer HG, Cole RM et al. Psychological aspects of chronic low back pain. Aust N Z J Surg 1996; 66:294-297.

73. Manchikanti L, Pampati V, Bakhit C et al. Effectiveness of lumbar facet joint nerve blocks in chronic low back pain: A randomized clinical trial. Pain Physician 2001; 4:101-117.

74. Manchikanti L, Pampati V, Bakhit C et al. Role of one day epidural adhesiolysis in management of chronic low back pain: A randomized clinical trial. Pain Physician 2001; 4:153-166.

75. Wallis BJ, Lord SM, Bogduk N. Resolution of psychological distress of whiplash patients following treatment by radiofrequency neurotomy: A randomized, double-blind, placebo-controlled trial. Pain 1997; 73:15-22.

76. Manchikanti L. Epidemiology of low back pain. Pain Physician 2000; 3:167-192.

77. Bigos SJ, Battie MC, Spengler DM et al. A prospective study of work perceptions and psychosocial factors affecting the report of back injury. Spine 1991; 16:16.

78. Schmidt AJM, Gierlings EH, Madelon LP. Environmental and interoceptive influences on chronic low back pain behavior. Pain 1989; 38:137-143.

79. Wiltse LL, Rocchio PD. Preoperative psychological tests as predictors of success of chemonucleolysis in the treatment of low back syndrome. J Bone Joint Surg [Am] 1975; 57:478-483.

80. Bradley LA, Prokop CV. Margolis R et al. Multivariate analysis of the MMPI profiles of low back pain patients. J Psychosom Med 1978; 1:253-272.

81. Graham JR. The MMPI-2: Assessing personality and pscyopathology. Oxford University Press, New York, 1990. 